\title{
LA ESTRUCTURA AGRARIA CHILENA \\ EN EL PERÍODO 1830 - 1900
}

\author{
Hernán Villablanca Z. \\ Dr. ScI
}

\begin{abstract}
INTRODUCCIÓN
El periodo 1830-1900 se caracteriza esencialmente por la expansión de las relaciones mercantiles en todos los sectores de la sociedad chilena y por la ampliación e integración del mercado interno. La agricultura de la zona central experimentó un auge notorio pero fluctuante, especialmente a partir de 1850 , debido a las oscilaciones de la demanda del mercado externo. Por su parte, el desarrollo de la minería, la construcción de ferrocarriles, caminos y obras públicas en general tuvieron entre otros, el efecto, de producir una relativa división de las grandes propiedades tradicionales, pero esto no significa que hayan experimentado una cambio significativo en cuanto a las técnicas de trabajo y de los cultivos.
\end{abstract}

\section{PRODUCCIÓN Y EXPANSIÓN DEL MERCADO AGRÍCOLA}

La economía chilena, en general, experimentó, entre 1830 y 1900 . una notable transformación. A este cambio contribuyó, en parte, la política económica aplicada por una serie de gobiernos que expresaban, principalmente en un comienzo, la alianza entre la clase terrateniente y la mercantil, en especial, al papel desempañado, al menos por algún tiempo, por esta última, que estructuraron y organizaron el Estado chilenoen todas las esferas de la vida política, económica, social y cultural del país.

Sin embargo, la posibilidad de llevar a cabo estas medidas se debió al cierto desarrollo experimentado por la economía como un todo y, en primer lugar, la minería y, luego, la agricultura. El descubrimiento y explotación de nuevos yacimientos de minerales, la gradual introducción del ferrocarril a lo largo y ancho del país, el mejoramiento y construcción de nuevos caminos, la construcción de canales, el impacto de la demanda externa en la producción de cereales y harina, etc..., fueron elementos que al actuar interrelacionadamente dieron gran impulso al desarrollo de la base económica del país y, al mismo tiempo, ampliaron e integraron el mercado nacional, conllevando todo ésto un mayor desarrollo de la economía mercantil y de formas incipientes de desarrollo capitalista. Pero, por otro lado, la creciente integración de la economía chilena al mercado mundial, la creciente influencia de los intereses cconómicos foráneos en la esfera política del país y la influencia de ideas políticas y económicas en boga en Europa, que no correspondían a la realidad e intereses de la sociedad chilena. fueron reforzando la estructura colonial o dependiente que se había generado en siglos anteriores. Esto frenó y deformó el proceso de estructuración de formas capitalistas de producción e hizo que 
la economía chilena quedara cada vez más expuestas a las oscilaciones y altibajos tanto del mercado como de los países de Europa y Norte América que se encontraban en una fase económica más desarrollada.

La situación financiera del gobierno chileno puede ser apreciada, en cierta medida a través de la relación entre ingresos y gastos. Entre los años 1832 y 1891 el ingreso promedio anual del gobierno de Chile fue de 21.231.338 dólares (dólares estadounidense de contenido oro de 1960), en tanto que el gasto promedio anual correspondió a 19.798.271 dólares. ${ }^{1}$ La entrada principal de los ingresos ordinarios provenía de aduanas por concepto de derechos de importación y exportación y por el de almacenaje impuesto a las mercaderías depositadas en los almacenes del Estado: el producto de las aduanas aumentó de 830.634 pesos en el año 1831 a 4.824.801 pesos en el año 1860 , a 7.690 .341 en 1874 y a 43.696 .362 pesos en el año $1890 .^{2}$

El valor promedio anual de las exportaciones aumentó de 12.290166 dólares en el período 1844-49 a 91.552.000 dólares en el decenio 1890-99. A partir de la década de 1860 el valor de las exportaciones superó al de las importaciones que, a su vez, aumentaron de 14.281.666 dólares en los años 1844-49 a 82.336.300 dólares en el período 1890-99. ${ }^{3}$

De acuerdo a F. Encina, «seguíamos pagando las mercaderías y los artículos tropicales con los productos de la minería. La agricultura continuaba abasteciendo el consumo interno y saldaba, exactamente como en 1810 , el 30 por ciento de las importaciones». ${ }^{4}$

El desarrollo de la producción agrícola del país se basó en la demanda del consumo interno y en la del mercado mundial. A su vez. la demanda del consumo interno estaba fundamentada, entre otros, en el constante incremento demográfico del país, en un relativo crecimiento del número de centros urbanos y en el desarrollo de la mincría cuyos conglomerados poblacionales se constituyeron en centros permanentes y significativos de consumo de alimentos.

Ambos mercados ejercieron influencia en el desarrollo mercantil de la agricultura y de la economía chilena, en general. Pero, mientras la demanda doméstica de trigo y harina crecía en forma lenta y regular, el mercado externo lo hacía a través de pronunciados altibajos. Se estima que el consumo interno (no el mercado, dice Bauer, por la imposibilidad de determinar la cantidad del producto suplido por la agricultura comercial y aquel que era producido para consumo directo por pequeños propietarios y trabajadores agrícolas), aumentó de 900.000 quintales métricos en cl quinquenio 1841.45 a 1.400 .000 en los años $1861-65$ y a 1.750 .000 quintales métricos en el quinquenio 1891 - 1895, y, por su parte, la exportación de ese producto aumentó de 125.000 quintales métricos en los años 1841 -45 a 1.524.000 en el quinquenio 1871 75, disminuye a 882 mil quintales métricos en el período 1886-1890, vuelve a subir en el siguiente lustro $1891-95$ a 1.455 .000 quintales métricos, pero en los años 1901-05 el volumen de la exportación de trigo ha disminuido a 385.000 quintales métricos. ${ }^{5}$

Tomando en cuenta casi exclusivamente el carácter exportador de la agricultura y, de ésta. solo la que corresponde a la zona central de Chile. A. Bauer distingue tres etapas durante el siglo XIX. La primera fase que se extiende hasta 1850. no sería más que una continuación del modo pastoril colonial, con limitadas exportaciones al Perú. La segunda etapa tendría su inicio durante los cortos períodos de prosperidad causados por los mercados de California y Australia en los años cincuenta, conllevando el surgimiento de la industria molinera y el cultivo más extendido de cereales, lo cual habría adquirido más importancia después de 1865 cuando se comenzó a exportar granos chilenos a Gran Bretaña. Por último, durante la tercera ctapa. de 1876 a 1895 . se habría producido la estagnación de la agricultura de la región central debido 
a la progresiva declinación de los precios mundiales del trigo causada, por una parte, por la competencia del trigo de los Estados Unidos. Rusia. Australia y Argentina y, por a otra parte. por las innovaciones técnicas en la molinería de Hungría y de los Estados Unidos. ${ }^{6}$

Aunque, en general, esta característica refleja la relación entre la producción de cereales de la zona central y el mercado mundial durante el siglo pasado, ella, a nuestro juicio, deja de lado un conjunto de otros elementos, reduciendo los rasgos de la agricultura de esa región casi exclusivamente al papel de la capacidad exportadora del sector agrícola. Aún cuandoel impacto de la demanda externa tuvo efectos muy significativos para el desarrollo ulterior de la agricultura, existen diversos factores internos, políticos, sociales, culturales, demográficos. etc..., que influyeron en el desarrollo económico total del país y que, a su vez, cran influidos por las nuevas características que iba adquiriendo el desarrollo. La agricultura es sólo una parte del todo económico y social y, por consiguiente, su caracterización debe estar estrechamente vinculada al desarrollo de otras ramas de la economía.

Así, el hecho de que se haya aplicado, hasta mediados de ese siglo, una política económica con ciertos rasgos proteccionistas contribuyó a que ciertas ramas o sectores económicos (artesanía, transportes, e incluso la agricultura) pudieran alcanzar un relativo de nivel de desarrollo. Por leyes del 30 de agosto de 1833 y de 8 de enero de 1834 se autorizó la importación de toda clase de mercaderías, siendo clasificadas éstas en dos categorias: las que se encontraban libres de derechos (en general, los elementos necesarios para el desarrollo de la ciencia y de la industria, tales como instrumentos de física, matemáticas y otros ramos científicos, maquinarias agrícolas, de la minería, libros impresos, útiles de imprenta, etc...), y las que se gravaban con derechos. Para estas mercaderías se establecieron cinco clases de derecho que variaban desde un cinco a un treinta y cinco por ciento. Teniendo en mente la protección de la industria nacional, se gravó en un treinta y cinco por ciento aquellas mercaderías como el calzado, ropa hecha y otros artículos similares. El trigo fue gravado con el llamado derecho de escala: 1.50 pesos por cada 150 libras de trigo extranjero, cuando el chileno no excediese del valor de cuatro pesos; cuando el valor de éste fuera de cuatro a cinco pesos, aquel pagaría el derecho de un peso: cuando el precio del trigo nacional fuese de cinco a seis pesos, el derecho de importación se reduciría a cuatro reales, y sería libre la internación el trigo extranjero cuando el precio del nacional pasase de seis pesos. Un derecho análogo se estableció a la importación de harina.

Hasta elaño 1848 la política proteccionista favoreció también a la marina mercante chilena. promulgándose leyes que tuvieron un carácter discriminatorio en favor de los navieros chilenos: «se ayudó a los armadores con privilegios y exenciones de impuestos y se mantuvieron estas normas a pesar de la oposición de sectores poderosos dentro de la economia». ${ }^{8}$. Sin embargo, esta y otras medidas proteccionistas no tuvieron larga duración. Las leyes proteccionistas promulgadas durante los años treinta fucron abolidas en el período $1848-59$ debido especialmente. dice C. Véliz, al impacto del descubrimiento de oro en California. Este proceso culminó con la promulgación de la Ordenanza de Aduanas de 1864 que consolidó el pensamiento libre cambista. ${ }^{9}$

Aunque el papel desempeñado por las diversas fuerzas socio-políticas internas y extemas en la liquidación de la legislatura proteccionista es objeto de un estudio posterior, estimamos necesario indicar algunas caracteristicas del pensamiento libre cambista y del proteccionismo chileno durante el siglo XIX. En Chile, la posición libre cambista se fue identificando, a lo largo del siglo pasado, cada vez más con ideales que, desde un punto de vista económico. significaba 
un perjuicio al desarrollo económico. esto es, tuvo un carácter conservador. Este hecho es una prueba más del carácter contradictorio del desarrollo y de los fenómenos económicos, sociales y políticos de un país. Por una parte. la interacción de las clases y fracciones de clases como la de los mineros del norte, de los terratenientes del centro y sur del Chile. y los importadores de bienes de consumo del centro, el creciente carácter exportador de la economía, la fuerza del mercado externo, etc..., son factores que condujeron al reemplazo del proteccionismo por el libre cambismo. Y, por otra parte, se da el caso paradojal de que los elementos liberales que abogaban por la democratización política del país, que objetaban cualquier incremento del poder central y que, al mismo tiempo, sustentaban ideales como la unificación de América Latina en una gran nación, fueron los más decididos defensores y propulsores del libre cambismo, en tanto, los que se identificaban con una posición más bien autoritaria que favorecía a un gobiemo central relativamente fuerte, abogaban por la aplicación de una política proteccionista. $^{10}$

Mientras este elemento social e ideo-político actuaba negativamente en el desarrollo de la industria manufacturera y, por tanto, en el desarrollo del capitalismo industrial del país, la acción de otros factores económico-sociales producía un efecto dinamizador de la economía en su conjunto y de la agricultura en particular.

La actividad minera, aunque con altibajos, fue un elemento que constantemente impulsó el desarrollo de la agricultura y de otras ramas económicas. El descubrimiento del yacimiento de plata de Chañarcillo, en el año 1832, marca el inicio de una continua actividad que más tarde. en el año 1870, recibe un nuevo estímulo con el descubrimiento de Caracoles. La explotación de la minería, en especial de la plata y el cobre, no hizo más que proseguir una actividad que provenía desde los tiempos de la colonia y que, hacia fines del tercer cuarto de siglo pasado. se centrará, hasta fines del primer cuarto del presente siglo, en la explotación del salitre.

Ha sido estimado que hacia los años 1840 había en explotación alrededor de 1.500 minas de oro. plata y cobre. ${ }^{11}$ Esta actividad repercutió directamente en las provincias del norte del país donde se formaron, en un tiempo relativamente corto, importantes conglomerados de población que contribuyeron a incrementar la demanda de productos agropecuarios. A comienzos de los años cuarenta, la provincia de Coquimbo contaba con una población que «Según el último censo ascendía a 103.679 habitantes, pero que probablemente pasaba de $120.000 \gg^{12}$ Por su parte, la ciudad de Copiapó, situada en esa misma provincia, fue experimentando un notable enriquecimiento y «formaba ahora un centro industrial y comercial más importante aún que la capital de la provincia ${ }^{13}$ Veinticinco años más tarde, en 1865 , la población de la provincia de Coquimbo ascendía a 145.895 habitantes y, en el año 1875, a 157.977 personas. Si a este número sumamos la población de la otra provincia del norte. Atacama. la cifra aumenta a 229.475 habitantes. La importancia de esta zona como centro de consumo adquiere mayor relevancia cuando, después de la Guerra del Pacífico (1879-83), se integran al territorio chileno las actuales provincias de Tarapacá y Antofagasta: en el año 1895 las llamadas regiones del Norte Grande (Tarapacá y Antofagasta) y las del Norte Chico (Atacama y Coquimbo) contaban con una población tolal de 376.624 habitantes, o sea, de 141.476 y 233.148 habitantes respectivamente. ${ }^{14}$

Aunque en menor medida, algo similar ocurrió en el sur, en la zona de Concepción. Hacia los años cuarenta del siglo pasado se inició allí la explotación del carbón de piedra. El conocimiento de una gran existencia de carbón en esa zona se remonta al tiempo de la llegada 
de los españoles, pero su explotación en forma estable. intensiva y en una cierta escala industrial comenzó a efectuarse sólo en los años cuarenta del siglo XIX. La necesidad de abastecer a las zonas mineras y a las fundiciones que se iban instalando y a las líneas de vapores transoceánicos que se fundaban, estimularon la explotaciớn del carbón: en el año 1853 se ocupaban en Lota y en Coronel a 122 personas en el trabajo de las minas. a fines del año 1854 ese número había aumentado a 900 personas, y en el año 1862 el centro minero de Lota contaba ya con una

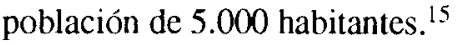

Por otro lado, el constante crecimiento demográfico es otro factor que contribuyó a un paulatino crecimiento de la demanda de alimentos y de productos de la agricultura: de 1.033.298 habitantes en el año 1835 la población del país aumento a 1.421 .161 en el año 1865 . 1.536 .193 en 1875 y a 1.774 .093 habitantes en el año $1895 .{ }^{16}$ Sin embargo, pese a este notorio crecimiento de la población, es difícil conocer con precisión su verdadera dimensión en la formación del mercado interno. Según A. Bauer, por las características de la estructura social del país, esencialmente agraria, no habría un mercado de importancia: «la sociedad chilena estaba dividida en dos grupos principales. Uno pequeño, residente en centros urbanos, con gustos refinados, algunos de los cuales eran satisfechos con exportaciones desde Europa... Aún cuando las clases altas hubiesen consumido solamente productos locales, su número cra demasiado escaso en el siglo XIX como para constituir un mercado importante... El segundo segmento, la masa de la población, se resignaba a una mera subsistencia. Muchos pequeños propietarios e inquilinos producían sus propios alimentos y por tanto representaban poco mercado para una agricultura comercial... ${ }^{17}$

Aunque la falta de datos impide conocer el volumen exacto de la producción agrícola mercantil, se puede sostener que el crecimiento demográfico fue, en cualquier caso, un elemento constante en la ampliación del mercado interno. En primer lugar, aunque es efectivo que durante todo el siglo XIX (y parte del XX) la población rural fue mayor que la urbana, se puede apreciar un permanente crecimiento de esta última lo cual está indicando una tendencia a la urbanización y por tanto a la formación de centros de consumo: en el año 1865 la población urbana representaba el 21.89 por ciento de la población total del país, en 1875 el 26 por cicnto. en 1885 el 28.59 por ciento. en 1895 el 34.19 por ciento y en 1907 el 37.83 por ciento. ${ }^{18}$ En segundo lugar, durante todo el período en estudio y, en especial. durante la segunda mitad del siglo pasado, se observan ciertos cambios en la estructura de la tenencia de la tierra. lo cual expresa. por un lado, un cierto grado de división de las grandes propicdades y, por otro. una mayor pauperización y despojo de los medianos y pequeños propietarios de sus medios de producción que, al ser «liberados» de sus medios de vida y de trabajo pasan a engrosar el número de personas que sólo dispone de su fuerza de trabajo. como mercancía que debe vender. para subsistir. Esto contribuiría a ampliar el mercado interior. Pero, estrictamente hablando, como cl proceso de acumulación originaria de capital en Chile poseía características específicas. diferentes del «patrón clásico» ya que el desarrollo de la manufactura e industria fabril tuvo un ritmo muy lento de crecimiento, gran parte de la población económicamente activa surgida del crecimiento demográfico y de la expropiación de los productos directos no tienen, o tienen sólo muy escasas, posibilidades de vender su fuerza de trabajo. En este sentido sería correcta la aseveración de $A$. Bauer en cuanto al carácter reducido del mercado agrícola intemo. Por consiguiente, la absorción de la cada vez más numerosa fucrza de trabajo disponible no ocurre en la industria manufacturera, como sucedió en páses como Inglaterra. sino se desplazó 
principalmente hacia la minería del cobre, carbón, plata, oro y posteriormente, del salitre. Otra gran parte de esa población se dirigió a los centros urbanos, otros se emplearon en la construcción de ferrocarriles y otras obras públicas, y una parte se dirigió a las tierras nuevas situadas al sur de Concepción.

El gradual crecimiento de los centros urbanos, que en sí es una cadena de causas y efectos, expresa el paulatino desarrollo de la economía mercantil. En este sentido J. Borde y M. Góngora han observado que... la población de Santiago, inmediatamente después de la Independencia, alcanzaba los 35.000 habitantes y sólo fue tomando vuelo hacia 1850; desde entonces ha ido duplicándose con regularidad cada veinte o veinticinco años, indiferente a fluctuaciones o eventos. De esta manera, la capital o incidentalmente su puerto (Conurbanización Valparaíso - Viña del Mar), han llegado a representar una proporción cada vez mayor de la población chilena y a constituir enormes mercados de consumo... Es probable que las exigencias de dicho mercado representen uno de los factores decisivos y quizás si el factor decisivo de la renovación completa de los campos circundantes. Esta demanda sin precedentes, especialmente de artículos de consumo perecederos y de productos de calidad, fue transformando en anacrónica la organización tradicional de la agricultura... ${ }^{19}$

En el año 1865 el 78.11 por ciento de la población total del país vivía en áreas rurales, veinte años más tarde ese porcentaje había disminuido a 71.41 por ciento, y en el año 1895 correspondía a un 65.81 por ciento. Al mismo tiempo, el número de centros urbanos de 2.000 a 20.000 habitantes aumentó de 36 en el año 1865 a 89 en 1895 , y los centros urbanos de 20.000 o más habitantes de 2 a 5 en el mismo período. ${ }^{20}$

Sin ser algo muy considerable, se puede apreciar un desplazamiento de la población agrícola hacia los centros mineros y a los centros comerciales urbanos con una incipiente industria manufacturera. Si observamos los datos porcentuales de la población por provincias se puede apreciar que la mayor concentración urbana se encuentra en las provincias mineras de Tarapacá y Antofagasta con un 59 y 56.7 por ciento respectivamente en el año 1885. y de 75.7 y 69.3 por ciento en 1895; a ellas les siguen las otras dos provincias nortinas, Atacama y Coquimbo, con 44 y 36.7 por ciento en 1885 y con 41 y 31.3 por ciento respectivamente en 1895 , cuyos porcentajes, aunque experimentaron una disminución con relación al decenio anterior. se encontraban por encima del porcentaje promedio del país de 38.6 por ciento. Los centros comerciales y manufactureros de Valparaíso y Santiago también presentaban una alta concentración urbana: de 70.2 y 61.9 por ciento respectivamente en el año 1885 y de 75.4 y 61.9 por ciento respectivamente en el año 1885 y de 75.4 y 66.7 por ciento en 1885 . En el sur del país la mayor proporción de población urbana. aunque ligeramente por debajo del porcentaje del país, se encuentra en Concepción con un 32.9 por ciento en 1885 y 45.2 por ciento en 1895 . csto es, por sobre el porcentaje nacional en esta última fecha. ${ }^{21}$

Por otra parte, este proceso de gradual desplazamiento de la población desde la agricultura a los centros urbanos comerciales, y con una incipiente industria manufacturera, puede ser apreciado también a través de las tasas de crecimiento de éstos: entre los años 1865 y 1895. la tasa promedio de crecimiento demográfico del país fue de 1.33 por ciento; las ciudades con 20.000 habitantes y más (excluida Santiago) tuvieron una tasa de crecimiento de 4 por ciento, las ciudades con 2.000 a 20.000 habitantes una tasa de 2.43 por ciento, Santiago de 2.7 por cicnto, y las zonas rurales de sólo 0.76 por ciento. ${ }^{22}$ 
Un elemento dinamizador de la economía, en general, y que contribuyó a absorver la fuerza de trabajo desplazada del campo fue la construcción del ferrocarril y, en general, de todas las vías de comunicación. Por ley del 17 de diciembre de 1842 se creó el cuerpo de ingenieros encargado de los caminos, puentes y todo lo relacionado con vías de comunicación. De acuerdo a esa ley los caminos fueron clasificados en públicos y vecinales. Caminos públicos son los que comunican una ciudad, villa o lugar con otra ciudad. Caminos vecinales son los que comunican los fundos particulares con los caminos públicos. En el año 1865 el país contaba con 475 caminos que con sus 14.933 kilómetros se extendía desde la provincia nortina de Atacama hasta la zona de Llanquihue en el sur y, hacia el año 1878, el número de caminos públicos había aumentado a 699 y tenían una extensión de 24.711 kilómetros; los caminos vecinales eran 1.562 y equivalían y equivalían a 17.863 kilómetros. $^{23}$

A partir del año 1850 se dio inicio a la construcción de los primeros ferrocarriles cuyos efectos en el plano económico y social del país tuvieron una importancia significativa. El 25 de diciembre de 1851 se inauguró el ferrocarril que unió el centro minero de Copiapó con el puerto marítimo de Caldera. Con este tramo de ochenta kilómetros se da comienzo a la construcción de la red ferroviaria que a lo largo de la segunda mitad del siglo XIX y parte del $\mathrm{XX}$, se extenderá por todo el país. Cinco años más tarde, en enero de 1856, se inauguró el tramo de ferrocarril que unió a Valparaíso con Quillota, y el 4 de julio de 1863 se completó esta línea uniéndose Santiago con Valparaíso.

Simultáneamente se efectuaban trabajos que extendían la red hacia el centro-sur del país. En diciembre del año 1859 el ferrocarril llegó a Rancagua ( 100 kilómetros al sur de Santiago), y en septiembre del año 1862 llegaba a San Fernando. Hacia el año 1878 el país ya contaba con 1.625 kilómetros en vías férreas y en el año 1891 el total de kilómetros en ferrocarriles llegaba a 2868 , de los cuales 1.106 eran de propiedad Estatal y 1762 kilómetros de propiedad privada. ${ }^{24}$

¿Cuáles fueron los efectos de esta actividad?. Según C. Hurtado, «la mayor parte de los cambios ocurridos, con posterioridad a 1850 , en la estructura de la sociedad chilena están en uno u otro modo estrechamente ligados al desarrollo del ferrocarril». ${ }^{25} \mathrm{De}$ acuerdo a ese autor. el desarrollo del ferrocarril tuvo el efecto, por una parte, de crear nuevas oportunidades de empleo surgidas de la demanda de mano de obra y otros insumos para la construcción y explotación de la red (se estima, por ejemplo, que en la construcción del ferrocarril de Santiago a Valparaíso se emplearon diez mil trabajadores, y, por otra parte, se crearon nuevas oportunidades de producción en casi todos los sectores de la economía chilena ( el consumo de los ferrocarriles demandó apreciables cantidades de carbón, durmientes, lastre, etc; cn el norte el ferrocarril permitió explotar los ricos yacimientos interiores, en la zona central hizo disminuir el costo de colocación de los productos agropecuarios en el mercado y favoreció a las localidades alejadas de los puertos o de los mercados de consumo) ${ }^{26}$ La importancia de este transporte también ha sido apreciada por D. Martner: «La utilización de los servicios de ferrocarril tenía obvias ventajas para los agricultores del valle central. Las estaciones estaban relativamente próximas a los centros productores y había un mínimo de trasbordos y manipulación. Los riesgos de pérdidas por naufragios u otras causas eran mucho menores que en el transporte por mar y la distribución en los terminales era mucho más sencilla y expedita. Además, debe mencionarse el hecho de que hasta fecha reciente. las facilidades portuarias en el litoral chileno eran francamente primitivas y las dificultades para embarcar y desembarcar mercaderías constituían obstáculo importante para la expedición de la carga». ${ }^{27}$ 
Todo indica que la introducción del ferrocarril y su efecto integrador del mercado nacional se manifestó directamente tanto en el comercio de cabotaje como en el de exportación. En el año 1862 , el movimiento de la carga de ferrocarriles fue de 5.333 .863 quintales métricos ${ }^{28}$. en 1878 la carga aumentó ligeramente a 5.915 .364 quintales métricos ${ }^{29}$. en el año 1891 se transportaron 15.269.025 quintales métricos, y en el año 1900 la carga transportada por los ferrocarriles llegaba a 22.291. quintales métricos, transportada mediante 3.990 carros ${ }^{30}$ Por otro lado, de acuerdo a publicaciones oficiales, la introducción del ferrocarril habría influido en el incremento del comercio exterior: la exportación del país, anterior a la existencia del ferrocarril (en 1853) equivalió a 12.138.000 pesos, y después de la introducción del ferrocarril, en 1878 , el valor habría aumentado a 31.695 .859 pesos. ${ }^{31}$

El notorio mejoramiento de las vías de comunicación ${ }^{32}$, fue un factor importante en la ampliación e integración del mercado interno. Sin embargo, la introducción y desarrollo del ferrocarril significó una mayor penetración de los intereses extranjeros en la economía del país. La construcción de los ferrocarriles chilenos, junto con producir, por cierto, un mayor desarrollo interno, sirvió para proveer una salida lucrativa para el capital y estimular la exportación de bienes de capital de los países industrialmente más desarrollados de Europa, en especial de Gran Bretaña y Norte América.

En primer lugar, sirvió a la inversión de capitales británicos: los cuatro ferrocarriles importantes del norte de Chile estaba en manos de las empresas inglesas Copiapó Railway Co. Ltd.,Coquimbo Railway Co. Ltd.,Tongoy Railway Co. Ltd., y Camizal Railway Co. Ltd., que en su conjunto giraban un capital de aproximadamente diez millones de pesos ${ }^{33}$. A fines de la década de 1890 las inversiones británicas en ferrocarriles «chilenos» alcanzaban la suma de 7.231.830 libras esterlinas, y el número de empresas había aumentado a nueve. ${ }^{34}$ En segundo lugar. sirvió a la inversión de capitales británicos bajo la forma de empréstitos al gobierno chileno: de nueve empréstitos contratados por el gobierno chileno entre 1822 y 1875 . tres (do 1858, 1870 y 1873) se concedieron para la construcción de los ferrocarriles de Santiago a Valparaíso, de Chillán a Talcahuano y de Curicó a Angol.$^{35}$ Y, en tercer lugar, contribuyó a la exportación de bienes de capital y de hierro desde los países industrialmente desarrollados: en el año 1878 el valor de la importación de bienes destinados a la locomoción. ferrocarriles y telégrafos fue de un valor de 330.210 pesos y el de máquinas y maquinarias, instrumentos y otros artículos para la industria, arte y oficios equivalió a 1.711 .793 pesos ${ }^{36}$ En el año $1890 \mathrm{el}$ valor de la importación de rieles fue de 1.975.432 pesos y el de hierros en barras y lingotes de 573.988 pesos. ${ }^{37} \mathrm{Y}$, en el año 1901. el valor de la importación de hierro y acero equivalió a 14.263.174 pesos, y el de la locomoción a 1.610 .852 pesos; del total de la importación gencral el 36.03 por ciento del valor de la mercadería importada correspondía a Gran Bretaña, el 24.67 por ciento a Alemania. el 11.86 por ciento a los Estados Unidos, y el 6.69 por ciento a Francia. ${ }^{38}$

Así, mientras, por un lado, la acción del mercado externo contribuía a impulsar el desarrollo de las fuerzas productivas y su desarrollo capitalista, por el otro lado, frenaba y deformaba este desarrollo, al mismo tiempo que integraba cada vez más la economía chilena al mercado externo y a las necesidades del desarrollo de los países industrializados del centro. Con ésto. la cconomía del país quedaba cada vez más expuesta a las vicisitudes del mercado mundial.

A partir de los años 1881-85 el precio del trigo comenzó a bajar tanto en Londres como cn Santiago. En Londres el precio de la fanega de trigo ( 71.5 kilogramos) que. en el quinquenio 1876-80 era de 4.26 pesos, disminuyó a 3.63 pesos en el lustro de 1881-85. a 2.83 en el 
quinquenio 18866-90, y a 2.52 pesos en los años 1891-95; el precio en Santiago de la fanega de trigo bajó de 3.38 (pesos de 44 peniques) en los años $1876-81$ a 1.85 pesos en el quinquenio $1891-95 .^{39}$

La disminución del precio del trigo en Europa y la incorporación de zonas más productivas y eficientes de otras partes del mundo en el mercado europeo colocaron a los terratenientes chilenos de la zona central del país en una desventajosa posición en la competencia mundial y, por tanto, imposibilitados de continuar exportando cereales. ${ }^{40}$ Sin embargo, esta declinación de la exportación de cereales de la zona central no parece significar un estancamiento de la agricultura de esa región. Más bien, durante esos años, se produce una cierta diversificación de la producción agrícola, en cuanto a frutas, vinos y legumbres: la producción vinícola de la región central aumentó de 143.646 hectólitros en el año 1862 a 200.895 en 1873 , y a 1.551 .654 hectólitros en el año 1914, o sea, hubo un aumento a una tasa anual de 4.7 por ciento; la producción frejoles se elevó a 90.030 quintales métricos en el año 1860 a 100.705 en 1873, a 255.633 en 1881 , y a 271.655 quintales métricos en el año $1908 .^{41}$

Asimismo, en el año 1869 se pueden anotar por lo menos 21 productos agrícolas diferentes, incluidos diversos tipos de vinos, y una existencia relativamente extensa de árboles frutales de explotación industrial: 144.493 olivos y 814.486 moreras, contándose para la producción de miel y cera con 75.050 colmenas. ${ }^{42}$ La exportación de cera y de miel de abeja aumentó de 1.637 kilógramos en el año 1879 a 2.005 kilógramos en el año 1902; en el mismo período la exportación de frejoles, garbanzos, etc. aumentó de $4.707 \mathrm{~kg}$. a $6.510 \mathrm{~kg}$., y la exportación de nueces de $1.223 \mathrm{~kg}$. a $3.233 \mathrm{~kg} .{ }^{43}$

Por otro lado, la declinación de la exportación de cereales y de harina de la zona central. a partir de los años ochenta del siglo pasado, no significa el desaparecimiento de ese cultivo en la zona: en los años 1880, 1885 y 1908. la producción de trigo fue de $3.218000,2.615 .000$ y 2.414.000 quintales métricos respectivamente. ${ }^{44}$ Todo esto indica, en primer lugar, que la zona central perdió su carácter esencialmente exportador de cereales y derivados para transformarse en zona abastecedora de productos agropecuarios del mercado interno, tanto para los crecientes centros urbanos de consumo de Santiago y Valparaíso como para las entonces recién incorporadas provincias de Tarapacá y Antofagasta, cuyas actividades mineras las convertían en importantes centros de consumo: «... a esta influencia (guerra del Pacífico) se añadió la apertura de los mercados consumidores de Antofagasta, Tacna y Tarapacá, que de antiguo se proveían en parte de Chile y que, después de la ocupación chilena, se surtieron de productos agrícolas casi exclusivamente del centro del país». ${ }^{45}$ El reavivamiento de la economía chilena por la Guerra del Pacífico y la consiguiente incorporación de nuevos territorios se expresó en el notorio incremento del comercio de cabotaje, lo cual también es un indicador del grado de crecimiento e integración del mercado interno: el cabotaje nacional aumentó en un 105 por ciento entre 1878 y 1882 . y en los años siguientes continuo subiendo vigorosamente; cl valor del comercio del cabotaje aumentó de 16.696 .921 pesos en 1861 a 31.187 .868 pesos en 1871 . a 59.240 .015 en 1881 , y a 103.792 .745 pesos en 1890.46

Y. en segundo lugar, se observa un traslado de la producción y exportación de cereales desde el centro a la zona que se extiende al sur de Concepción: la producción de trigo en la Frontera aumentó de 70.000 quintales métricos en el año 1880 a 877.000 en 1885 . y a 1.807 .000 quintales métricos en $1908 .{ }^{47}$ Así, en tanto que en la zona central la exportación de trigo Jescendió de 382.000 quintales métricos en los años 1881-85 a 86.000 en el período 1886-90. 
y a 84.000 quintales métricos en el quinquenio 1896-1900. la exportación de trigo de la región de la Frontera fue, en el mismo período, de 700.000. 750.000 y 600.000 quintales métricos respectivamente. ${ }^{48}$

\section{TENENCIA DE LA TIERRA Y ESTRUCTURA SOCIAL}

La característica principal de la propiedad agrícola durante la segunda mitad del siglo XIX y, en especial a partir de los años ochenta, es la tendencia a una relativa subdivisión de la gran propiedad y una gran multiplicación de la pequeña y mediana propiedad de la zona central del país. El número de grandes propiedades (de un ingreso anual superior a seis mil pesos) aumentó de 145 en 1854 a 338 en 1875 y a 504 en $1908 .^{49}$

En general, esta tendencia a formar unidades agrícolas de producción algo más pequeñas esta estrechamente ligada al aumento del valor de la tierra. En este sentido, este proceso se observa primero en las tierras de regadío cercanas a Santiago y. en la medida que el ferrocarril $y$ los caminos de acceso se extienden hacia el sur, se extenderá el mismo fenómeno. ${ }^{50}$ Esto es. si bien el incremento de la población continúa siendo un común denominador en los sucesivos períodos de fragmentación, su papel, que era casi exclusivo a fines del siglo XVIII y comienzos del XIX, pasa a desempeñar un papel secundario: «Los factores que prevalecieron entonces, ofrecieron en su mayoría. aquella particularidad de traducirse en una valorización de la tierra. valorización sin duda mercantil. pero también valorización intrínseca bajo la forma de agua. caminos, mercados, mano de obra». ${ }^{51}$

El trabajo de J. Borde y M. Góngora sobre la propiedad rural en el valle del Puange comprueba que en esta zona se pone término, en el período 1860-80. a dos siglos de estabilidad de las tradicionales estructuras territoriales.

Esta zona ha sufrido, de acuerdo a los autores mencionados, dos olas de fragmentación. La primera. la antigua, iniciada en el siglo XVIII, fue provocada por el aislamiento y la pobreza de las tierras que entonces favorecieron el desmembramiento de los patrimonios familiares al ritmo de las sucesiones. ${ }^{52}$ La segunda apareció al promediar los años $1860-80$ y se divide en dos fases cuyo hito marcatorio puede situarse alrededor del año $1930 .^{53}$

¿Qué factores incidieron en la fragmentación. especialmente en la primera fase de la segunda ola?. Aunque el factor económico está siempre subyacente, hay un conjunto de elementos, tales como el relieve, el regadio, las carreteras, demográficos, innovaciones técnicas. presencia del mercado. hábitos, valores. etc... que constituyen una compleja interrelación de causa y efectos que. de acuerdo al momento histórico dado, uno de ellos o una combinación de ellos, ejerce la acción principal del cambio.

Así. del análisis efectuado por J. Borde y M. Góngora sobre la mencionada subdivisión de la tierra se pudo determinar que lo que a primera vista, parecía encerrar una estrecha correlación entre la fragmentación y relieve adquiría caracteres mucho más complejos cuando se examinaba el papel de los diferentes tipos de tierra a través del tiempo. Para dichos autores el relieve intervino sólo de una manera indirecta en la fragmentación a través de la economía rural y de las capacidades agrícolas propias de cada terruño. ${ }^{54}$ La presencia de cerros en las haciendas de la zona estudiada tuvo diversos efectos. Permitió a aquellos propietarios, dueños de tierras planas y de cerros, desplazar el ganado hacia los cerros y dejar disponible las tierras planas para 
cultivo de cereales cuando se produce el incremento de la demanda externa por este producto, sin la necesidad de trastornar la base de su economía y la organización de sus heredades. Asimismo. los cerros, junto con ser mantenedores de las estructuras económicas tradicionales, contribuyeron a retardar la evolución de las estructuras sociales de la gran propiedad: «Cuando la llanura empezó a verse invadida por una agricultura especializada, los cordones montañosos se constituyeron en reserva de pasto y leña indispensable para una mano de obra pagada de preferencia en especies más que en efectivo. fueron ellas, en cierto modo, para la hacienda y sus inquilinos lo que había sido para las aldeas europeas de otros tiempos los bosques y dehesas comunales». 55

Pero, antes de que se iniciara la diversificación de la producción agrícola, agregan esos autores, la presencia de los cerros ejerció una influencia más bien favorable a la fragmentación, «porque proporcionaron tierras de distintas aptitudes a pequeñas explotaciones familiares que vivían en economía cerrada (predios en forma de fajas del siglo pasado) y, sobre todo, entregaron la agricultura a mediocres rendimientos. Al alcanzar la fragmentación cierto grado crítico la propiedad territorial, en la incapacidad de asegurarse nuevas inversiones mediante sus beneficios, fue partiéndose al ritmo de las herencias». ${ }^{56}$

En cuanto a la relación entre fragmentación y regadío, los autores estiman que la ausencia de regadío, o el pequeño riego local, favoreció tanto al latifundio como al minifundio, en tanto que la subdivisión moderna, aunque menos avanzada por lo general, se ha desarrollado preferentemente en los lugares donde penetran las aguas de la Gran Cordillera». ${ }^{57}$

Más clara es la relación e influencia de la carretera en la subdivisión de la tierra lo cual no sería otra cosa que la influencia de la ciudad sobre el campo ${ }^{58}$ Las zonas favorecidas por la presencia de carretera experimentaron una notoria fragmentación reforzada, en muchos casos, por el ferrocarril cuando sigue el trazado de esas carreteras. por otro lado, dicha relación presencia de carretera o ferrocarril y fragmentación- se hace más evidente por el contraste que ofrecen aquellas zonas donde no ha llegado la carretera y el ferrocarril, en las cuales la estructura de la gran propiedad mantiene conservadoramente sus antiguos límites. ${ }^{59}$

Se puede decir, entonces, que la fragmentación experimentada por la gran propiedad en el valle del Puange, durante la segunda mitad del siglo XIX. se debe a que el llano, el regadío y la carretera «constituyen, pues, conforme a dosificaciones y modalidades difíciles de precisar, el medio favorable a la subdivisión de la tierra". ${ }^{60}$

Al lado de estos factores es necesario, sin embargo, mencionar algunos otros tales como el demográfico, el proceso técnico, el mercado, etc.

Aún cuando la zona central venía experimentando un regular crecimiento demográfico por lo menos desde comienzos del siglo XVIII, no es posible aseverar, dicen los autores, que este incremento demográfico rural haya tenido una influencia inmediata sobre la partición de las tierras. A su juicio, ciertas costumbres sucesorales y una relativa disponibilidad de bienes muebles, de dinero efectivo o de patrimonios diseminados a lo largo del territorio del país, que permitían compensar adecuadamente a todos los herederos favoreció el que las haciendas, como regla general, pudieran sobrevivir por dos o tres generaciones. ${ }^{61}$

Tampoco consideran plausible la hipótesis de que la ola de subdivisiones iniciada en la segunda mitad del siglo XIX sea una manifestación retardada del impulso demográfico, porque en la totalidad del territorio las fragmentaciones son más bien una excepción, características de las grandes regiones periurbanas. ${ }^{62}$ Estiman, más bien, que la relación entre incremento 
demográfico y subdivisión de la tierra tiene caracteres más complejos, porque se encuentra ligada a elementos tales como venta y trabajo.

Al introducir en la mencionada relación el factor mercado, ya que «la ola de desmembramiento moderno ha sido demasiado consecutivo con el desarrollo de los grandes mercados de consumo» ${ }^{63}$, aquella deja de ser una relación directa de causa y efecto: «viene a situarse el concepto de mano de obra en el centro de una red de interdependencia que unen al régimen agrario con los tipos de cultivo, las rentas por hectárea, las vicisitudes del mercado y la densidad de la población». ${ }^{64}$

Por otra parte, la evolución demográfica fue adquiriendo características que ya no conducían a un círculo cerrado de excedentes de nacimientos sobre defunciones. Hay, en cambio, una creciente acción interviniente del factor trabajo en la provocación de los movimientos migratorios: «tan sólo podemos retener como esquema provisorio y de un valor burdamente aproximativo, el hecho que el incremento natural de la población, más o menos continuo, si descartamos alguna crisis de origen epidémico o las recientes conquistas de la higiene, ha sido obliterado por dos fuerza opuestas, ya simultáneas o sucesivas, tendientes la una a distraer la mano de obra hacia los centros mineros y urbanos y la otra hacia el campo. los que se enriquecían a medida que iban ampliándose sus mercados . ${ }^{65}$

Además, el incremento de la subdivisión territorial, en la segunda mitad del siglo pasado, puede ser explicado, a juicio de J. Borde y M. Góngora, por un aflojamiento de las estructuras familiares tradicionales causado por el proceso de democratización que iba experimentando el país: « Aparecieron elementos nuevos entre los compradores de la tierra y tendieron a desplazar a la antigua aristocracia de los hacendados. Ello dio como resultado una mayor movilidad de la propiedad, un número creciente de ventas y transacciones. ${ }^{66}$

Pero, en cualquier caso, este relajamiento de las estructuras familiares tradicionales no es un elemento causal suficiente para explicar la fragmentación. En cierta medida, y dentro del contexto de los otros factores, también es preciso señalar la influencia del progreso técnico en la agricultura. Se puede apreciar una coincidencia cronológica entre la construcción de los grandes canales y la subdivisión de la tierra, correspondencia que, para los autores, «...no puede atribuirse exclusivamente al azar y nos permite agregar al número de causas evidentes de la fragmentación de la propiedad, la perforación de los canales ${ }^{67}$ Pero, agregan a continuación, este adelanto en el regadío debe ser inserto dentro de un marco más amplio de renovación técnica de uso de la tierra, dentro del cual se inscriben también el desarrollo de las carreteras, ferrocarril, selección de las especies y fertilización del suelo. ${ }^{68}$

Las escasas series estadísticas disponibles indican la existencia de un cierto sincronismo entre la ligera mejora de los rendimientos y la subdivisión de la propiedad, pero, este aumento del rendimiento se debería más a adelantos en el sistema de regadíos y a la irrupción de las aguas andinas (que penetran en el valle poco después de 1880) que a un perfeccionamiento de las lécnicas agrícolas. ${ }^{69}$

Más evidente y directa es la relación entre el crecimiento de la ciudad-mercado y la fragmentación y carıbio de la estructura agraria. Se ha observado una absoluta contemporaneidad entre la fragmentación de las grandes heredades y el auge de la exportación del trigo de la zona del Puange. Y. al producirse la declinación de la exportación de los cereales de la región central del país. la agricultura del Puangue fue solicitada por nuevos mercados (Norte del país y Santiago). Según Borde y Góngora, y al menos para el valle del Puangue. la influencia del 
mercado de Santiago representa muy probablemente el factor decisivo de la renovación de los campos circundantes. ${ }^{70}$ Sin embargo. la acción de los mercados tuvo efectos distintos en momentos diferentes. En los años setenta y ochenta del siglo XIX, la economía rural de esa región, basada en la asociación de la siembra y exportación de cereales con la ganadería, pudo mejorar los rendimientos y ganancias por hectárea, gracias al regadío, sin trastomar la estructura social de las grandes haciendas y sin mayor necesidad de incrementar la mano de obra. Esto originaba un desequilibrio entre las ciudades en plena expansión y las densidades rurales de más lento crecimiento. En cambio, cuando la agricultura se orienta, entre los años 1920 y 1930, hacia el aprovisionamiento de los grandes mercados urbanos y cuando emprende la diversificación de su producción, « se vio en la obligación de emplear y mantener apegada a la tierra una mano de obra cada vez más numerosa. Así fue como las fragmentaciones modernas... vieron disminuir en forma apreciable el contraste entre la demografía urbana y la demografía rural de las provincias de Santiago y Valparaíso». ${ }^{71}$

La influencia de la ciudad en el cambio de la estructuras socio-económicas de los campos circundantes se manifestó de diversas maneras. En general, en el valle del Puangue, las vías férreas, las carreteras, la irrigación, la conquista de mercados exteriores, etc..., esto es, todo lo que ejerce influencia en la generación de cambios se debió a la proximidad de Santiago. ${ }^{72}$ En particular, esta proximidad facilitó el que se produjera una mayor rotación y subdivisión de la propiedad por la compra de sectores sociales «no tradicionales» (comerciantes e industriales enriquecidos, empleados, etc.), que creen encontrar una especie de seguridad y consagración social a través de la adquisición de una explotación agrícola: «Cuando la Caja de Colonización Agrícola puso en venta sus terrenos de Las Lumbreras y de Puangue, un 50 por ciento de los compradores confesaron residir en Santiago ( 9 comerciantes. 1 médico, 1 ingeniero, 2 rentistas y 7 agricultores)». ${ }^{73}$

Por último, en cuanto al papel del crédito en la evolución de la propiedad en el Puangue, se puede decir que la organización del capital, del crédito y de las finanzas públicas contribuyó. en general, a la transformación de la estructura agraria al hacer de la propiedad un objeto de transacciones. Pero, en particular, el crédito tuvo más bien una influencia opuesta, conservadora, sobre el régimen agrario. El crédito, al ser otorgado casi exclusivamente a los latifundistas y al estar prácticamente controlado por ellos, se convirtió en un instrumento de conservación de la estructura agraria debido, especialmente, a la continua desvalorización de la moneda chilena que transformó a los créditos en verdaderas donaciones de préstamos a largo plazo. ${ }^{74}$

A nuestro juicio, es necesario hacer más explícitas algunas de las ideas subyacentes en el análisis de J. Borde y M. Góngora. Sin duda, el proceso de democratización del país y el quiebre de ciertos valores tradicionales son expresiones de una mayor diferenciación social, resultante de la evolución económica de Chile, que indica la presencia de nuevas clases y grupos sociales que tienen la capacidad económica y el interés social. por el prestigio que ello implica. de adquirir propiedades agrícolas. Esto tuvo, a su vez, diversos efectos económicos y sociopolíticos. Desde este último punto de vista, dado que los nuevos compradores provenían principalmente de círculos mineros, comerciales y banqueros muchos de los cuales, o sus descendientes, se unieron en matrimonio con antiguas familias de le «elite» chilena se produjo. como había sucedido en siglos anteriores, una confluencia de intereses entre aquellos sectores sociales. ${ }^{75}$ Esto adquiere mayor relevancia si consideramos que a su vez los terratenientes desempeñaban o van a desempeñar paralelamente diversas actividades económicas (bancos. 
compañías de seguros, firmas comeciales, ecc.). Desde un punto de vista económico. la incorporación de estos sectores sociales a la agricultura significó que gran parte de los mejoramientos técnicos efectuados en el agro fuera realizado por estos nuevos compradores.

Ahora. al examinar la situación de los pequeños y medianos propietarios se puede apreciar al menos en el departamento de Caupolicán ( $130 \mathrm{Km}$. al sur de Santiago), que, en general, la pequeña propiedad sufrió, entre 1853 y 1917, un profundo proceso de fragmentación: el número de propiedades menores de 5 hectáreas aumentó de 358 en el año 1853 a 3.401 en 1917; el número de propiedades entre 5-20 hectáreas se elevó de 440 a 555; el de propiedades entre 21-50 hectáreas se mantuvo prácticamente igual (164 y 162); y el número de aquellas entre 21 y 200 hectáreas aumentó de 90 a $163 .^{76}$

Este proceso de fragmentación de la pequeña propiedad ha sido observado también en la zona de Putaendo, Entre 1809 y 1869-1878, la proporción de predios agrícolas de media cuadra o menos se triplicó, esto es, la propiedad de la mencionada superficie que en el año 1809 constituían el 28.8 por ciento del total de las propiedades, en los años 1869-1878 representaban el 78.3 por ciento del total. ${ }^{77}$

Todo ésto. junto con indicar una notoria difusión del minifundio, muestra que en el mencionado período se acentuó el proceso de pauperización de los pequeños propietarios.

Es muy probable que en los predios pequeños, además de los factores que contribuyeron a la fragmentación de la gran propiedad, la acción de elementos como el demográfico deben haber ejercido una influencia mayor y más directa que en el caso del latifundio. Dicho factor debe haberse manifestado con más fuerza a través de la participación por herencia, ya que el pequeño propietario no disponía de los recursos necesarios para compensar con otros bienes a los herederos.

Al mismo tiempo. casi con seguridad se puede decir que un elemento decisivo en la fragmentación de la pequeña propiedad y la pauperización del pequeño propietario fue sus escasa o ninguna capacidad económica para enfrentar las crisis económicas y las malas cosechas.

Entre 1830 y 1891 el país sufrió a lo menos tres grandes crisis económicas, las de los años 1857-61, de 1876-78 y la de 1884-86, y otras tantas perturbaciones de la naturaleza.

El país todavía no se reponía del terremoto de 1835 (que afectó a la región de Talca al sur) cuando debió enfrentar una fuerte sequía en la región centro-sur: «Los campesinos abandonaban sus hogares y acudían a los pueblos en busca de ayuda y alimentos. Hubo que trasladar al norte de Maule a las mulas hambrientas que deambulaban en vano, por las haciendas y poblaciones». 78

Todo parece indicar que la crisis económica de los años 1848-50 sólo tuvo repercusiones indirectas en la economía chilena al retrasar algunos proyectos de obras públicas. ${ }^{79}$ En todo caso. sus posibles efectos negativos fueron prontamente superados por el auge económico producido por la demanda de los mercados de California y Australia. Más bien la pérdida de estos mercados, la declinación de la minería de la plata, los dos años consecutivos de malas cosechas. y las repercusiones de la crisis económica mundial de los años 1857-61, fueron los elementos principales que provocaron la profunda crisis cconómica que afectó a la agricultura y otros sectores cconómicos en el año 1857: «La crisis comercial hubo de repercutir por fucrza en agricultores, mincros e industriales... los mineros tuvieron que reducir sus instalaciones y mejoras emprendidas. Los más provocaron quicbras estruendosas... El precio de la propiedad 
rural bajó en un 40 por ciento. Para colmo de fatalidades, la crisis se complicó con una verdadera hambruna en el Maule... La cosecha de trigo de enero y febrero de 1857. en esta provincia, había sido muy pobre. Como quiera que los agricultores y molineros tenían vencimientos impostergables, vendieron para la exportación en los primeros nueve meses del año, al precio que pudieron lograr... Los campesinos tampoco habían guardado los productos de la chacarería cosechados en abril del año fatal en cantidad suficiente para suplir la falta de trigo... En septiembre apareció el hambre entre los pequeños propietarios e incluso entre algunos inquilinos de la hacienda, en trágico maridaje con la desocupación, pues, al paralizar los grandes agricultores las mejoras después de concluida la siembra, suspendieron todos los trabajos". ${ }^{80}$

La economía chilena que comenzaba a recuperarse de las perturbaciones de la crisis de fines de los años cincuenta debido, en particular, a la reactivación de la actividad minera de la plata por el descubrimiento, en al año 1870 , del yacimiento de Caracoles, junto con ser un estímulo para la economía del país, se convirtió en uno de los factores causantes de la crisis. Su descubrimiento desató una fiebre bursátil que, al exagerar la capacidad real de las reservas de plata del mencionado yacimiento, provocó la quiebra estrepitosa de numerosas sociedades formadas sobre la base de tales cálculos irreales. ${ }^{81}$

La crisis económica en Europa y Norte América fue otro elemento que, sumado al anterior. contribuyó a una mayor contracción de la economía de Chile. Y las tres malas cosechas que se sucedieron hasta el año 1877 provocaron la ruina de numerosos agricultores, en especial, de los pequeños y medianos propietarios: «Las tres malas cosechas... colocaron a los agricultores en la imposibilidad de servir el interés de sus deudas y la cartera bancaria quedó en gran parte inmovilizada. La buena cosecha de 1873 permitió a algunos regularizar su situación, pero muchos perdieron sus propiedades. o parte de ellas. Llegó un momento en que faltaron los compradores que dispusieran de recursos necesarios para adquirir fundos por el monto de la deuda, sin más exigencia que ponerla al día y dotarlos de animales para proseguir la explotación. Muchos acreedores, e inclusive al gunos bancos. se vieron obligados a pagarse con predios rústicos». ${ }^{82}$

Por último, la crisis de los años 1884-86, que primero afectó a Europa y luego a las otras regiones del mundo. hizo que los precios del trigo bajaran en Londres a 2.89 pesos lo cual significó que el trigo chileno fuera cotizado a un precio máximo de 1.40 pesos. ${ }^{83}$

Sin embargo, las crisis económicas y las malas cosechas no tuvieron el mismo efecto entre los distintos propietarios agrícolas. Como ya ha sido mencionado. los terratenientes empezaron a recibir, desde 1865 , ayuda del gobierno para reducir sus deudas, cuya medida de pagar el interés de algunas obligaciones eclesiásticas permitió a los propietarios agrícolas «rescatar alrededor de veinte millones de pesos correspondientes al valor de los censos y capellanías entre 1865 y $1890 m .84$

Por otra parte. el creciente proceso inflacionario les proporcionó un doble beneficio. Como los salarios agrícolas subían más lentamente que los precios, mantuvieron los márgenes de ganancia en forma más consistente en el mercado doméstico. Y, los préstamos ventajosos que recibían (hasta 1880 los más comunes fueron las letras al 8 por ciento de interés pagaderas a veintiún años, y. desde esa fecha, se convierten en letras que comienzan a emitirse al seis por ciento de interés, extendiéndose el plazo de pago a veinticinco años). al no invertirse en la agricultura se convirtieron en verdaderos suplementos del ingreso agrícola. ${ }^{85}$ 
En cambio, el crédito a los pequeños propietarios, inquilinos y medieros, se canalizaba a través de la hacienda con lo cual se incrementaba el control de los terratenientes sobre los pequeños productores. Hasta alrededor del año 1865. tanto los inquilinos y medieros como los pequeños propietarios recibían préstamos en dinero directamente del hacendado o mediante especies a través de la pulpería que los terratenientes acostumbraban a tener en sus haciendas. Desde el año recién indicado, al necesitarse más mano de obra en las haciendas, el hacendado comenzó a anticipar semilla y a arrendar equipos y, con frecuencia, a suministrar dinero a estos productores a cuenta de la futura cosecha ${ }^{86} \mathrm{~A}$ través de la pulpería, la hacienda se convirtió, además de ser la principal unidad productiva del agro, en un centro de distribución de productos y artículos de todo tipo, siendo también así la principal unidad comercial de la sociedad rural. ${ }^{87}$

Los pequeños propietarios se encontraban prácticamente excluidos de la posibilidad de recibir créditos de bancos o de otras organizaciones similares:...« en Talca, por ejemplo, sólo cinco por ciento del total del crédito otorgado fue en forma de préstamo de novecientos noventa y nueve pesos o menos, mientras que un sesenta por ciento estaba constituido por unidades de crédito de cinco mil pesos o más. En Caupolicán, un departamento que se caracteriza por la polarización en minifundios y latifundios, el ochenta y cuatro por ciento del total se otorgaba en créditos de cinco mil pesos o más, y sólo el cuatro por ciento a pequeños deudores». ${ }^{88}$

Al lado de ésto, los créditos a los pequeños agricultores eran concedidos en condiciones mucho menos favorables que a los latifundistas: «...la mitad de los deudores en el año 1862 , por ejemplo, pagaron interés entre el 18 y el 24 por ciento... La categoría inmediatamente superior de deudores, aquellos que reciben préstamos que oscilan entre 1.000 y 4.999 pesos, está compuesta por medieros más prósperos y propietarios de fundos de tamaño mediano. Hay un significativo mejoramiento en las condiciones de los préstamos que éstos recibieron. En 1862 , sólo ocho de los treinta y cinco deudores pagaron más de 18 por ciento de interés, mientras que la mitad de ellos recibe préstamos con intereses que van del ocho al once por ciento». ${ }^{89}$

La expansión del cultivo del cereal, a partir del año 1850, tuvo también el efecto de incrementar la interdependencia económica entre el gran propietario y el pequeño productor, crecientemente basada en el dinero efectivo, ${ }^{90}$ lo cual. claro está, se tradujo en una mayor dependencia de este último con relación al latifundista.

Además de la mediería tuvo gran difusión la práctica de lo que denomina «venta en yerba o venta en verde», esto es, la venta por parte del mediero o del pequeño propietario de la planta al estado verde o con el grano formado, pero sin cosechar. ${ }^{91} \mathrm{O}$ sea, se reducía a la venta anticipada del grano el cual era comprado a un precio muy por debajo al del mercado. usualmente en un cien por ciento menos. ${ }^{92}$

Si a esta práctica, que de hecho conducía al endeudamiento de los pequeños propietarios. sumamos los períodos de malas cosechas (a veces dos y tres años consecutivos). es fácil concluir que de este modo también los pequeños propietarios debían finalmente vender sus tierras para poder pagar sus deudas.

Al ser «liberados» de sus medios de producción, el pequeño propietario pasó a engrosar las filas de la población flotante. disponiendo ahora solamente de su fuerza de trabajo para subsistir.

La población flotante aumentó notoriamente durante la segunda mitad del siglo XIX. estando constituida especialmente por peones o gañanes que se desplazaban de un lugar a otro en busca de trabajo. Una parte de ella trabajó en la construcción de los ferrocarriles chilenos 
y peruanos: en la construcción del ferrocarril de Valparaíso a Santiago trabajaron, entre los años 1852 y 1863 , alrededor de 10.000 mil hombres por año. y se estima que, entre 1868 y 1872 , 25.000 - 30.000 trabajadores chilenos se trasladaron al Perú para trabajar en el tendido de vías férreas en ese país. ${ }^{93}$ Otra parte de la población emigró hacia la zona minera del norte, a los centros urbanos de la región central y a las «tierras nuevas» de Concepción al sur. Según C. Hurtado, entre 1865 y 1907, la emigración del núcleo central fue de 481.000 personas, en tanto que la población de la región de Concepción y la Frontera aumentó, por efecto de la inmigración, en 266.000 habitantes en ese mismo período; los centros urbanos de la zona central en 311.000 y las regiones del Norte Grande y Chico en 34.000 habitantes ${ }^{94} \mathrm{Al}$ mismo tiempo, entre 1850 y 1880 , muchos peones comenzaron a establecerse en pequeños terrenos que constituyeron la base de un gran número de caseríos y villorrios de los cuales los hacendados podías abastecerse de una mano de obra estable y barata. ${ }^{95}$ Sin embargo, la poca capacidad de la gran propiedad de absorver fuerza de trabajo y el estado muy incipiente de la industria manufacturera determinó la presencia de una gran masa de desocupados que se desplazaban por el país: hacia el año 1963 en la región central de Chile cerca del sesenta por ciento $(59.000)$ de una población masculina de 101.000 fue considerada por el censo como «personas sin residencia o destino fijo ${ }^{96}$

Pero, mientras, por un lado, la pauperización de los pequeños propietarios acrecentaba el número del proletariado rural, urbano y minero, contribuyendo de este modo a provocar cambios en las relaciones sociales de producción, por el otro, se observa al interior de la hacienda una tendencia a reforzar las formas tradicionales de apropiación del trabajo excedente no retribuido.

Según A. Bauer, el impacto de los crecientes mercados y la consiguiente expansión del cultivo de cereales produjo cambios en el sistema de inquilinaje. En primer lugar, se ampliaron las exigencias al inquilino. Así, la obligación, que existía antes de 1850, de aportar con servicios de un peón obligado fue aumentada a dos e incluso a tres trabajadores cuyos salarios eran de responsabilidad del inquilino, aportando la hacienda sólo la ración diaria de comida ${ }^{97}$ En segundo lugar, a los nuevos inquilinos que se incorporaban a la hacienda se les redujeron las regalías en comparación con los antiguos: se les redujo el tamaño de las tierras asignadas. El nuevo inquilino, reclutado entre los peones-gañanes, pasó a constituir una nueva categoría de trabajador, el inquilino-peón opeón sedentario que además del terreno asignado (más reducido) recibía un pequeño salario. ${ }^{98}$

Este empeoramiento de las condiciones de vida se hizo sentir también entre los peones. Sobre la base de una numerosa cantidad de datos dispersos, A. Bauer ha podido determinar que el salario de los peones permaneció constante a lo largo del siglo XIX: en los años 1830-50 el salario promedio diario de los peones era de 15-20 centavos, en 1861-70 alcanzaba a 25 centavos y en los años 1871-80 era de 30 centavos; pero, si se considera el alza de los precios en diversos artículos de primera necesidad. se puede concluir que el salario real había disminuido hacia fines del siglo pasado. ${ }^{99}$

En general, los hacendados eran contrarios o reacios al pago en dinero, pudiéndose decir que esta forma de remuneración no fue frecuente durante el siglo pasado. ${ }^{160}$ La competencia provocada por los trabajos del ferrocarril y obras públicas, y la emigración en general. fue enfrentada por los latifundistas en diversas formas. Trataron de promulgar leyes que impidieran o limitaran el éxodo de la población, o bien, recurrieron a la ayuda del clero: «Directivas fueron 
enviadas por los obispos a cada párroco mediante las cuales se les instruía atacar la destrucción de la vida familiar que podría causar la emigración». ${ }^{101}$

En gran parte esta situación fue superada, como ya ha sido indicado, por los cambios experimentados por la estructura agraria: gran parte de los peones fueron absorvidos por la gran propiedad a través de una ampliación del inquilinaje, aunque en condiciones más desfavorables que antes de 1850; al mismo tiempo, entre 1850 y 1880, muchos peones comenzaron a establecerse en pequeños terrenos que constituyeron la base de un gran número de caseríos y villorrios, y además, por la rápida fragmentación de la pequeña propiedad sus dueños debieron optar por trabajar parte de su tiempo en las haciendas o emigrar. ${ }^{102}$

\section{CONCLUSIONES}

Aún cuando los datos censales no entregan una información segura sobre la estructura ocupacional, especialmente porque no se definen con precisión las diferentes categorías y subcategorías empleadas, sus datos, en general, corroboran el carácter de los cambios experimentados por la estructura social del campo. La población clasificada como «gañanes», esto es, aquellas personas que de acuerdo al Censo del año 1865 »... se emplean en faenas del campo durante ciertas temporadas del año, regresando a las ciudades cuando concluyen aquellos trabajos» ${ }^{103}$, aumentó de un total de 124,787 en 1854 a 179.255 en 1865 , a 188.530 en 1875 , y a 225.131 en 1907. En cifras relativas, los gañanes constituían el 8.67 por ciento de la población total en 1854 , el 9.85 por ciento en 1865 , el 9.08 por ciento en 1875 y el 6.92 por ciento en el año 1907 . Los jornaleros propiamente tal disminuyeron de 9.111 en 1854 a 3.533 en 1865, aumentaron a 4.282 en 1875. no apareciendo esta categoría en el Censo de 1907.

Por otra parte, el número de «agricultores», categoría que aparece incluir tanto a grandes propietarios, medianos y pequeños como a inquilinos y medieros, aumentó de 108.510 en 1854 a 166.939 en 1865 y a 173.741 en 1875 , disminuyendo a 65.578 en el año 1907 . O sea, los agricultores que en el año 1854 constituían el 7.54 por ciento de la población total del país, disminuyeron proporcionalmente a 6.42 por ciento en el año 1865 , aumentó esta proporción a 8.36 por ciento en 1875 , y disminuyó nuevamente a 6.96 por ciento (incluidos agricultores y labradores juntos) en 1907.

Los datos estarían indicando que la población flotante formada por los gañanes experimentó un aumento entre los años 1854 y 1875, y su número menor en 1907 indicaría que una parte de esta población se habría «estabilizado» en los centros mineros de las nuevas provincias del norte del país y en los crecientes centros urbanos de la zona central en donde se habrian integrado al trabajo de la incipiente industria manufacturera. formarian parte de nuevas formas de trabajo (trabajadores "por cuenta propia», por ejemplo), o simplemente engrosaría el número de cesantes de las ciudades. Algo parecido habría sucedido con los agricultores. Su número y proporción aumentó entre 1854 y 1875; su disminución hacia el año 1907 podría deberse, en gran parte, a una cierta declinación del inquilinaje en todas o alguna de sus formas.

De acuerdo a A. Bauer, el número de agricultores, en la zona central de Chile, aumentó, entre los años 1865 y 1895 , de 24.000 a 68.000 lo cual refleja, "entre otras cosas. la extensión que tuvo el inquilinaje con la ampliación del cultivo de granos». ${ }^{104} \mathrm{Y}$. al mismo tiempo, agrega este autor, que la declinación del número de peones de 59.000 a 43.000 fue parcialmente un 
problema de definición censal y el resultado de la emigración, todo lo cual indica el cambio de patrones agrarios que estarían estrechamente ligados a la rápida fragmentación de las pequeñas propiedades. ${ }^{105}$

\section{NOTAS}

1. Carlos Hurtado, Concentración de Población y Desarrollo Económico. El Caso Chileno. Santiago, 1966. p. 165. cuadro 20.

2. Para los años 1831 y 1860 en Censo Jeneral de la República de Chile levantado el 19 de abril de 1865 , Santiago 1866. p. 349; para el año 1874 en Quinto Censo Jeneral de la Población de Chile levantado el 19 de abril de 1875. Valparaíso, 1876, p. 658; para el año 1890 en F. Encina, op. cit., vol. 19. p. 401.

3. C. Hurtado, op. cit., p. 150, cuadro 10.

4. F. Encina, Resumen de la Historia de Chile, op. cit., vol. 2. pp. 1143-44.

5. A. Bauer, «Expansión Económica en una Sociedad Tradicional: Chile Central en el Siglo XIX», en Historia. Universidad Católica de Chile, Santiago, 1970, pp. 139-40.

6. Id., pp. 141-42.

7. Rafael Sotomayor Valdés, Historia de Chile durante los Cuarenta años transcurridos desde 1831 hasta 1871. Santiago de Chile, 1875, vol. 1, pp. 219-21.

8. C. Véliz, op. cit., p. 66 .

9. Debido a que casi todos los barcos chilenos que zarparon a California cargados de trigo y de provisiones se quedaron allí, en pocos meses Chile se vio enfrentado a la situación de tener casi todos los puertos menores del Nonte y Sur del país poco menos que bloqueados por falta de aprovisionamiento. Los mineros del nonte y los agricultores y comerciantes del centro y sur del país abogaron por la apertura del cabotaje a todas las banderas. Pese a la oposición de otros sectores sociales, especialmente de los navieros chilenos. el 4 de septiembre de 1849 se decretó la apertura del cabotaje, autorización que fue continuamente prorrogada. (C. Véliz, op. cit.. pp. 79-90 y 91 ).

10. Id., pp. 263-66.

11. D. Barros Arana, Historia de Chile (1841-1851), Santiago, 1905, vol. 1, pp. 119.

12. Id., p. 361.

13. Id., p. 361.

14. C. Hurtado, op. cit., p. 183, cuadro 29.

15. F. Encina. Resumen de la Historia de Chile, op. cit.. vol. 2, pp. 1161 y 1167.

16. C. Hurtado, op. cit., p. 144, cuadro 2.

17. A. Bauer, «Expansión Económica...», op. cit., p. 138.

18. C. Hurtado, op. cit., p. 145, cuadro 3.- Un enfoque similar es sostenido por T. Wright, quien sostiene que el número de consumidores-compradores de productos agrícolas aumentó de 333.482 en el año 1865 a 554.207 en 1885 . a 742.908 en 1895. y a 1.127.912 en el año 1907. (Thomas C. Wright, «Agriculture and Protectionism in Chile. 18801930 », en Journal of Latin American Studies, (7,1), p. 49, cuadro 2).

19. J. Borde y M. Góngora, Evolución de la propiedad rural en al Valle del Puangue, op. cit., vol. 1, p. 138.

20. C. Hurtado. op. cit., p. 145, cuadro 3, y p. 149, cuadro 9.

21. Censo de la República de Chile levantado el 28 de noviembre de 1907. Santiago, 1908, p. 1262.

22. C. Hurtado, op. cit.. p. 148, cuadro 8.

23. Censo Jeneral de la República de Chile... 1865. op. cit.. p. 330, y Anuario Estadístico de la República de Chile correspondiente a los años 1877 y 1878 , tomo XX. Santiago, 1879. p. 489.

24. Oficina Central de Estadística, Anuario Estadístico de la República de Chile, vol. 12: Comunicaciones. Año 1921: Santiago, 1922, p. 125.

25. C. Hurtado. op. cit., pp. 63-64.

26. Id., pp. 64-65.

27. Daniel Martner, Nuestros Problemas Económicos, El Tráfico Naciomal, Santiago, 1918, pp. 29-31. cutado por C. Véliz. op. cit., p. 233.

28. Anuario Estadístico de la República de Chile (entrega quinta). Vias Píblicas, Santiago. dicienbre de 186.3. p. 458.

29. Anuario Estadístico de la República de Chile correspondiente a los años 1877 y 1878 . op. cit.. p. 489. 
30. Sinópsis Estadística y Geográfica de la República de Chile en 1900. Santiago 1901, pp. 87 y 89.

31. Anuario Estadístico... correspondiente a los años 1877 y 1878 op. cit.. p. 489 . A su vez. A. Bauer señala que al llegar la línea central a Curicó en 1870 y a Talca cuatro años más tarde. el porcentaje de harina exportado a través de Valparaíso aumentó de menos de 25 por cientoen los años 1846-50 a más de 90 por ciento en 1880 . Al mismotiempo. agrega Bauer, esto provocó una nivelación de los precios de las propiedades agrícolas a lo largo del país. (A. Bauer, «Expansión Económica...», op. cit., pp. 151 y 195).

32. Además de la construcción de caminos y ferrocarriles, se instalaron líneas telegráficas: en el año 1875 éstas tenían una extensión de 5.298 kilómetros. se contaba con 59 oficinas y se transmitieron 241.513 telegramas; por su parte, los correos contaban, ese mismo año, con 17 administraciones principales, 54 locales y 257 estafetas, y se transportaron 15.107 .353 piezas. (F. Encina, op. cir., vol.15, p.45

33. H. Ramírez N., Historia del Movimiento Obrero en Chile, Santiago, 1956, p. 29.

34. F. Rippy, «Notes and Comment. The British Investment «Boom» of the 1980"s in Latin America», en HAHR, May 1949, vol. 29, № 2, p. 283, cuadro 2.

35. H. Ramírez N., Historia del Movimiento..., op. cit., p. 55.

36. Anuario... correspondiente a los años 11877 y 1878 , op.cit.p. 48

37. Sinópsis Estadística y Geográfica de la República de Chile en 1893, Santiago, 1894, p. 139.

38. Mentoria del Ministro de Hacienda presentada al Congreso Nacional en 1903, Santiago, 1904, pp. 300, 303 y 305 .

39. A. Bauer, «Expansión Económica...». op. cit., p. 168, cuadro II-4.

40. Id., p. 175.

41. C. Hurtado, op. cit., pp. $72-73$ y 162 , cuadro 17 y 18 .

42. F. Encina, op. cit., vol. 14, pp. 623-24.

43. Memoria del Stuperintendente de Aduanas sobre la Renta y el Comercio Exterior en 1902, Valparaíso, 1903. p. 39.

44. C. Hunado. op. cit., p. 161, cuadro 16.

45. F. Encina, op. cit. vol. 17, p. 419.

46. H. Ramírez N. Historia del Movimiento..., op. cit., p. 178. Para los años 1881 y 1890 en F. Encina, op. cit., vol.17. p. 417 y vol. 19. p. 405: para el año 1861 en Anuario Estadístico de la República de Chile (entrega quinta). Comercio Exterior, Santiago, diciembre de 1863.p. 383, cuadro 11; para el año 1871 en Censo de 1875, op. cit., p. 671.

47. C. Hurtado, op. cit., p. 161, cuadro 16.

48. A. Bauer, Chilean Rural Society.op. cit. p. 85.

49. Jd., pp. 175 y 176.

50. Id., p. 175.

51. J. Borde y M. Góngora. Evolución.... op. cit., vol. 1. p.141.

52. Id., p. 109.

53. Id., p. 140

54. Id., p. 97

55. Id., p. 98.

56. Id., pp. 98-99

58. Id., pp. 107-108.

59. Id., pp. 106-107.

60. Id., p. 109.

61. Id. p. 111.

62. Id., p. 112

63. Id. p. 112.

64. Id., p. 112.

65. Id., p. 113

66. Id., p. 116.

67. Id. p. 119.

68. Id.. p. 119.

69. Id., p. 122.

70. Id. pp. 137-38.

71. Id. p. 138.

72. Id. p. 140.

73. Id. p. 140. 
74. Id. pp. 125-27.

75. A. Bauer. Chilean Rural Society.... op. cit. pp. 179 - 181

76. A. Bauer, «The Hacienda El Huique in the Agrarian Structure of Nineteenth-Century Chile», en Agricultural History. 1972. p. 463. cuadro 4.

77. R. Baraona y otros. op. cit. pp. 200 y $205-6$, cuadro IX/7.

78. F. Encina, Resumen de la Historia de Chile, op. cit., vol. p. 954.

79. D. Barros Arana, Historia.(1841-1\&51), op. cit.vol. 1, p.1

80. F. Encina, Resumen..., op. cit., vol. 2, pp. 1188-89.

81. F. Encina, Historia de Chile, op. cit., vol. 15, pp.406-408

82. Id. vol. 16, p. 65.

83. A. Bauer, «expansión...», op. cit., p: 175.

84. Id., p. 175.

85. Id., pp. $176-77$ y 194.

86. Id., pp. $180-81$ y 201.

87. A. Bauer, Chilean Rural Society..., op. cit., p. 96.

88. Dado que la propiedad no podía hipotecarse por un valor superior a la mitad de su avalúo, una hacienda tenía que valer por lo menos diez mil pesos para cumplir los requisitos de conseguir un préstamo de cinco mil pesos: «se requería una propiedad de un tamaño relativamente grande-bastante mayor al de la típica «granja familiar»-para obtener préstamos de más de 5.000 pesos. Como era de esperarse, el aumento del crédito fue casi enteramente a beneficiar a los grandes propietarios». (A. Bauer, «Expansión...», op. cit., p. 183.

89. A. Bauer, Chilean Rural Society.... op. cit., p. 203.

90. Id., p. 204.

91. Id., p. 204.

92. Id., pp. 205-206.

93. Id., p. 152.

94. C. Hurtado. op. cit., p. 146. cuadro 4.

95. A. Bauer, «Chilean Rural Labor in the Nineteenth Century», en The American Historical Review: vol. 76. No 5, December 1971, pp. 1069-70.

96. Id., p. 1074.

97. Id., pp. 1074-75.

98. Id. pp. 1075-76.

99. Id., p. 1080.

100. Id., p. 1081

101. Id., p. 1081.

102. Id., pp. $1082-83$.

105. Censo del año 1865 , op. cit.. p. 343.

104. A. Bauer, «Chilean Rural Labor...», op. cit., p. 1082.

105. Id., pp. 1082-83. 